\title{
Intereses: Cuándo, cuánto y cómo. Actualidad y rol en las indemnizaciones de daños y perjuicios
}

Interests: When, bow much and how. Topicality role in within the área of compensation for damages

Interesses: Quando, quanto e como. Atualidade e papel na compensação por danos e prejuizos

Intérêts: quand, combien et comment. Actualité et rôle dans l'indemnisation des dommages 兴趣: 何时, 多少以及如何. 新闻和损害赔偿的作用

\section{Rosario Echevesti ${ }^{1}$ \\ Universidad Nacional de La Plata - Argentina}

Revista Derechos en Acción ISSN 2525-1678/ e-ISSN 2525-1686

Año 5/NNo 15, Otoño 2020 (21 marzo a 20 junio), 69-84

DOl: https://doi.org/10.24215/25251678e389

Recibido: 01/03/2020

Aprobado: 01/04/2020

Resumen: El propósito de esta breve reseña es el de aportar al lector una serie de elementos que puedan resultar efectivos y actuales a la hora de definir, en situaciones concretas, la manera, el tiempo y la cantidad de intereses que genera un capital de dinero. Esto, con particular foco en las indemnizaciones que resultan impuestas por sentencias judiciales.

Palabras clave: intereses, obligaciones de dinero, indemnización, reparación

\footnotetext{
Abogada (UNLP), Especialista en Derecho Civil (UNLP), Magister en Derecho Civil Patrimonial (UCA), Profesora Adjunta de Derecho Privado II (Obligaciones) de la UNLP. (ORCID 0000-0002-4960-2120). Correo electrónico: roechevesti@gmail.com
} 
Abstract: The purpose of this brief review is to provide the reader with a series of elements that can be effective and updated when defining, in specific situations, the manner, time and amount of interest that money capital generates. This, with particular focus on the reparations that are imposed by judicial sentences.

Keywords: interest, money obligations, compensation, reparation

Resumo: 0 objetivo desta breve revisão é fornecer ao leitor uma série de elementos que podem ser efetivos e atuais ao definir, em situações específicas, a maneira, o tempo e a quantidade de juros que o capital monetário gera. Isso, com foco particular nas compensações impostas por sentenças judiciais.

Palavras-chave: juros, obrigações monetárias, compensação, reparação

Résumé: Le but de cette brève revue est de fournir au lecteur une série d'éléments qui peuvent être efficaces et actuels lors de la définition, dans des situations spécifiques, de la manière, du temps et de la somme des intérêts générés par le capital monétaire. Pour cela, on va mettre le centre sur les compensations qui sont imposées par des arrêts judiciaires.

Mot-clés: intérêts, obligations, argent, compensation, réparation

摘要：本简短回顾的目的是向读者提供一系列在特定情况下定义货 币资金产生的利息的方式,时间和金额时可能有效且有效的要素. 这 尤其关注司法判决所施加的赔偿.

关键词: 利息, 货币义务, 赔偿, 赔偿

\section{Introducción: intereses. Concepto e importancia}

El dinero, al igual que otros bienes, es apto para producir frutos, a los que llamamos intereses. Esto quiere decir que determinada cantidad de dinero, bajo ciertas circunstancias, puede devengar más dinero en el patrimonio de su propietario.

Muchas son las definiciones que -sin mayores discordanciasha dado la doctrina sobre el concepto de interés, centrándolo principalmente en uno de sus enfoques en tanto fruto civil que produce el dinero, y destacando primordialmente su carácter 
accesorio. También es considerado como un medio sancionatorio, en el caso de los intereses punitorios y sancionatorios.

El interés entonces es el "aumento paulatino que experimentan las deudas de dinero, en razón de su importe y del tiempo transcurrido, prorrata temporis" .

Ahora bien, el propósito de esta breve reseña es el de aportar al lector una serie de elementos que puedan resultar efectivos y actuales a la hora de definir, en situaciones concretas, la manera, el tiempo y la cantidad de intereses que genera un capital de dinero. Esto, con particular foco en las indemnizaciones que resultan impuestas por sentencias judiciales.

Esta circunstancia ha tomado un rol sumamente importante en un país como Argentina, en donde la fluctuación del valor adquisitivo del dinero ha sido una constante; y es por eso que mucho se ha discutido y escrito sobre la cuestión.

No está de más aclarar, previo adentrarnos en otras cuestiones, que las obligaciones pueden adquirir matices diferenciados según su objeto, modalidades, etcétera. Así, existirán obligaciones que -por sus circunstancias- nacen y se extinguen sin que los intereses entren en juego, y habrá otras en las que jugarán un rol significativo. De allí que resulta necesario como premisa inicial al momento de analizar un caso concreto, diferenciar de manera clara el objeto debido, como también el momento de nacimiento de la obligación, el de su exigibilidad, el de la eventual mora, el de liquidez de la deuda y el del pago cancelatorio.

Para comenzar, abordaremos brevemente dos conceptos que no siempre han sido distinguidos de manera clara, arrastrando a confusiones: las deudas de dinero y las deudas de valor.

\section{Deudas de dinero y deudas de valor}

Conocemos que el valor del dinero, es decir, aquello que determinada cantidad de dinero puede comprar, ha variado y varía

2 Llambías, Jorge J., "Tratado de Derecho Civil, Obligaciones", t. I-A, Ed. Perrot, Bs. As., 1994, p. 205 
con el paso del tiempo. Partiendo de ese concepto es que resulta útil la diferenciación de deudas de dinero y deudas de valor.

La ley civil se ocupa de darnos una definición suficiente de las primeras. Así, establece el Art. 765 que "la obligación es de dar dinero si el deudor debe cierta cantidad de moneda, determinada o determinable, al momento de constitución de la obligación...". Esto quiere decir que una obligación de dar dinero tendrá por objeto, desde el momento mismo de su génesis, una suma determinada de dinero. La alusión de "determinable" refiere a aquellas cuya liquidación resulte de una mera operación matemática. Entender lo contrario implica volver a confundir los campos porque -ya veremos- toda deuda de valor es finalmente determinable en dinero.

En la deuda de valor, el objeto es una utilidad a la que el acreedor tiene derecho, la cual ha de medirse en el momento de liquidación de la deuda ${ }^{3}$. Estas deudas tienen entonces, dos momentos bien diferenciados: el de su nacimiento -en el que se expresan mediante un valor- y el de su liquidación -en el que se traducen a dinero, para ser canceladas-

La distinción entre ambas especies toma real relevancia cuando se la analiza en consonancia con los principios que las rigen. En nuestro país, las deudas de dinero se hallan atadas a la regla nominalista, encontrándose prohibida su actualización (art. 7 ley 23.928 texto según ley 25.561). De no ser así, la diferencia no tendría la trascendencia -teórica ni práctica- que tanto ha ocupado a nuestra doctrina y jurisprudencia.

Así, la característica más importante que en nuestro régimen tienen las obligaciones de dar sumas de dinero es que en ellas se aplica, como adelantamos, el principio nominalista rígido. Esto quiere decir que se cancelan entregando la cantidad estipulada de moneda, sin que sea viable ningún tipo de modificación. Lo expuesto implica que, aunque el dinero pueda

3 LLAMBIAS, Tratado de Derecho Civil, Obligaciones, Abeledo Perrot, 5ta edición, Buenos Aires, 2005, tomo II A p. 167 
tener fluctuaciones en su valor -lo que antes podía comprar con esa cantidad de dinero, ya no lo puedo comprar hoy-, la deuda dineraria quedará a salvo de dichas vicisitudes. Como consecuencia, la entrega de la suma consignada constituye un pago íntegro y cancelatorio que no puede ser rehusado por el acreedor -siempre, claro está, que lo sea en el tiempo y lugar que correspondan- . Esto se encuentra respaldado por nuestra ley civil en su artículo 766 que claramente establece que el deudor debe entregar la cantidad correspondiente de la especie designada ${ }^{4}$, en consonancia con lo que ya regulaba la ley 23.928 en su art 7 hoy vigente, y cuya aplicación ha sido reiteradamente avalada por nuestros tribunales 5 .

Por el contrario, en las deudas de valor, lo que se debe es un cierto valor abstracto o una utilidad, representada por bienes, pero no la entrega de esos bienes -que por otro lado, no siempre es posible-. Esto significa que la deuda habrá de medirse en dinero como máximo al momento del pago. Hasta que ese momento arribe, se debe un valor cuya traducción en dinero puede ir variando, lo cual no modifica el objeto debido porque justamente el mismo, consiste, si se quiere, en la cantidad de dinero que equivale al valor de determinado bien, al momento del pago. Como veremos, aquí el principio nominalista no juega ningún rol.

Ejemplo típico de una deuda de valor es la indemnización por daños y perjuicios derivada de un hecho ilícito o de un incumplimiento contractual. En estos casos -y sin perjuicio de que la obligación de indemnizar habrá nacido en el momento del daño-, la valuación del daño se hará a la fecha de la sentencia. Allí es donde se determinará el monto de la indemnización, o en

\footnotetext{
4 Aclaramos que la especie, para obligaciones dinerarias, siempre debe tratarse de moneda de curso legal, de lo contrario, la obligación se considera como de dar cantidades de cosas, tal como lo establece el art. 765 in fine.

5 CSJN, in re Belatti, Luis Enrique c. F.A. s/cobro de australes del 20/12/2012; CSJN in re Bedino Mónica Noemí c/ Telecom Argentina S.A. y otro del S 14/3/2017; SCBA in re Correa, Oscar Jesús c/ Carboclor Industrias Químicas S.A.I.C. s/ Indemnización enfermedad causa 86189 del 29-8-2007; in re Da Silva, Miguel Angel y otro c/ Transportes La Perlita S.A.y otro s/Indemnización causa 92958 del 3-6-2009, entre otros.
} 
otras palabras, cuando el juez establecerá, en términos de dinero, el quántum de ese daño. Los intereses, en estos casos, tomarán, según el tipo de que se trate -v.g. moratorios, compensatoriosun rol diferenciado. De ello nos ocupamos más adelante.

Pero claro, en las circunstancias con las que nos encontramos al ejercer el derecho, no siempre aparecen los ejemplos de libro.

Lo que debemos tener presente es que toda deuda de valor, está llamada a convertirse en una de dinero, al sólo efecto de ser cancelada. Es que el dinero es el bien de intercambio por antonomasia, y la moneda de curso forzoso y legal, es el modo de cancelar las obligaciones dinerarias que por excelencia admite nuestro derecho. Las deudas de valor deben ser "liquidadas". A partir de allí se modifica su objeto, se convierten en dinerarias y quedan alcanzadas por el régimen normativo de esta tipología, en particular por el principio nominalista rígido ${ }^{6}$. A partir de allí no podrán, como regla, ser actualizadas.

\section{Diversos tipos de intereses}

Cuando hablamos de intereses, si bien se trata de un concepto específico, debemos tener en cuenta que existen diversos tipos dentro del mismo. Las diferentes variables del interés, están llamadas a cumplir funciones bien distintas. Muy brevemente pasamos a caracterizarlas:

Los intereses compensatorios son el precio que se debe pagar por el uso y disfrute de un capital ajeno.

Pueden ser de origen convencional o legal, y se encuentran actualmente regulados en nuestro Código Civil y Comercial, Art. 767: "Intereses compensatorios. La obligación puede llevar intereses y son válidos los que se han convenido entre el deudor y el acreedor, como también la tasa fijada para su liquidación. Si no fue acordada por las partes, ni por las leyes, ni resulta de los usos, la tasa de interés compensatorio puede ser fijada por los jueces".

6 Pizarro, Ramon D. "Los intereses en el Código Civil y Comercial", Publicado en: LA LEY 31/07/2017, 31/07/2017, 1 - LA LEY2017-D, 991 
Los intereses moratorios, por su parte, tienen la función de reparar el atraso en el cumplimiento de la obligación, siempre que sea imputable al deudor. Con ello, su presupuesto es la existencia de mora en el cumplimiento de la obligación, es decir, ese incumplimiento relativo del que tanto se ha ocupado nuestra doctrina. Como consecuencia, donde no hay o no puede haber mora, no hay o no puede haber daño moratorio, y por ende, tampoco intereses moratorios.

Estos dos tipos de intereses -compensatorios y moratorios-, pueden en principio acumularse, ya que responden a dos causas distintas.

Por último, están los intereses punitorios. Para gran parte de nuestra doctrina, los intereses punitorios son los moratorios establecidos por las partes en sus convenciones, pero también pueden verse como una pena privada, o una sanción al incumplimiento. En caso de estar previamente establecidos por las partes, actúan como una verdadera cláusula penal. Pero igualmente la ley puede preverlos como sanción a la falta de cumplimiento, por ejemplo en cuestiones tributarias. De estas características se desprende una naturaleza diversa respecto de los otros tipos de intereses, ya que suman una función y utilidad diferenciada -sancionatoria y/o disuasiva-.

Finalmente mencionamos a los intereses sancionatorios, que actúan como pena para el incumplimiento de las cargas y mandas procesales, ante una inconducta procesal maliciosa.

\section{Entonces, ¿qué obligaciones generan intereses?}

Un análisis superfluo de todo lo expuesto podría llevarnos a concluir de manera apresurada que las obligaciones de dar dinero llevan intereses, y las de valor no.

Ello no es así, dado que el generar o no intereses, depende de varias otras circunstancias, como también de qué tipo de intereses estemos hablando.

Recordemos que, a los efectos de ser canceladas, y por ende, para evaluar si generan intereses, las deudas de valor requieren 
ser liquidadas. Tal vez esta circunstancia es la que hace factible la confusión.

Pero veamos: cualquier deuda puede contener intereses compensatorios, siempre que deba retribuirse por la privación del uso del capital durante el tiempo pactado, es decir, el tiempo en que el acreedor fue privado de ese capital.

Los intereses moratorios, en general se relacionarán con una deuda de dinero. ¿Por qué? Porque su presupuesto es la mora. Y no se puede entrar en mora por una obligación que no está liquidada porque no es, en principio, posible su pago.

De este modo, es posible que una deuda dineraria que genere intereses moratorios tenga como antecedente una de valor -v.g., en un juicio por daños y perjuicios, una vez liquidada la indemnización a valores actuales y vencido el plazo para abonarlas-. Pero, reiteramos, debe encontrarse liquidada -en definitiva, ya convertida en deuda dineraria- y con el plazo de cumplimiento vencido.

\section{Diversos tipos de tasas de interés. Tasa aplicable}

Ahora bien, para discernir en cada caso cuánto ha generado un capital en concepto de intereses, debemos recurrir a una tasa.

La tasa en sentido lato, ha sido definida como el rendimiento de la unidad de capital en una determinada unidad de tiempo ${ }^{7}$. Es un coeficiente que, en determinado tiempo y lugar, representa el precio del dinero en el mercado financiero. Pero también, cuando hablamos de "tasa", suelen incluirse dentro de sus componentes porcentajes que encuentran su causa y función en otras cuestiones. A estos dos aspectos se los ha llamado "rendimiento" del capital" -en tanto rédito que produce el dinero-, y "escorias", tales como la desvalorización de la moneda, el riesgo cambiario, etc ${ }^{8}$.

\footnotetext{
7 Pizarro, Ramón D. ob cit

8 Ver Pizarro-Vallespinos, “Manual de Obligaciones". Ed Rubinzal-Culzoni, Santa Fe, 2019, Tomo I p. 263 en donde se desarrollan los diversos componentes de la "escoria".
} 
La tasa a aplicar, depende del tipo de interés que estemos tratando.

Cuando se habla de "tasa pura", se está haciendo referencia a aquella que representa la rentabilidad razonable de un capital, despojada de cualquier otro elemento -como podría ser la mora-. La tasa pura compensa el "no disponer" de un capital que es propio, durante cierto tiempo. Es decir, se aplica para el interés compensatorio.

Nuestra ley no aporta un porcentaje fijo para la tasa de interés puro, pero nuestros tribunales la han justipreciado en entre un 6 y un $8 \%$ anual, siendo hoy doctrina jurisprudencial vigente la que establece la alícuota en un $6 \%$. Esta tasa es la aplicable a intereses compensatorios, siempre que no hayan sido establecidos de otra manera por la autonomía de las partes (Art. 958 CCCA).

En cuanto a la tasa de interés moratorio, desde la entrada en vigencia del nuevo Código Civil y Comercial de la Nación, la pauta del art. 622 del Código de Vélez -que disponía que, a falta de interés convencional o legal, "los jueces determinarán el interés que debe abonar"-, ha sido derogada. La norma que viene a reemplazarlo establece -también para el supuesto de ausencia de interés legal o convencional, que es lo que sucede en la mayoría de los casos de responsabilidad aquiliana- que la misma se determinará "en subsidio, por tasas que se fijen según las reglamentaciones del Banco Central" (art. 768 inc. "c").

9 El interés puro fue establecido por la Corte Suprema de Justicia de la Nación en un $6 \%$ anual (Fallos: 283:235; 295:973; 296:115, y más recientemente en Fallos: 311:1249). Nuestra Suprema Corte de Justicia provincial, en un primer momento lo determinó en el 8 \% por igual período (v. causas Ac. 20.458, "Sinagra de Fernández", sent. de 26-XI-1974, AyS 1974-III-747; Ac. 21.175, "Acosta", sent. de 23-IX-1975, AyS 1975-845; Ac. 39.866, "Martín", sent. de 21-II-1989, AyS 1989-I-141), pero luego, a partir de lo resuelto en B. 48.864 ("Fernández Graffigna", sent. de 1-X-1983, AyS 1983-III-227) se plegó a la señalada alícuota de un 6 \% anual (v. causas L. 49.590, "Zuñiga”, sent. de 1-VI-1993; L. 53.443, "Fernández", sent. de 6-IX-1994; L. 60.913, "Amaya", sent. de 14-X-1997; L. 73.452, "Ramirez", sent. de 19-II-2002; Ac. 85.796, "Banco de la Provincia de Buenos Aires", sent. de 11-VIII-2004; C. 95.723, "Quinteros", sent. de 15-IX-2010; C. 99.066, "Blanco de Vicente Fanny", sent. de 11-V-2011; e.0.). 
En los fundamentos del anteproyecto, se lee respecto de esta cuestión que "no se adopta la tasa activa como se propiciara en el Proyecto de 1998, porque se considera que hay supuestos de hecho muy diversos y es necesario disponer de mayor flexibilidad a fin de adoptar la solución más justa para el caso".

Ahora bien, ¿esto debe entenderse en el sentido de que el Banco Central deberá fijar una tasa única para el interés moratorio judicial? ¿O que, existiendo varias tasas, dentro de ellas el juez puede elegir la aplicable? Así, puede interpretarse que existe libertad para que el juez seleccione una de aquellas "tasas bancarias", o bien que debe existir una única y uniforme, determinada por el Banco central. Ambas interpretaciones han sido sostenidas por autorizada doctrina al analizar el artículo ${ }^{10}$.

Pero veamos entonces esta otra clasificación de "tasas" que se ha introducido: la llamada tasa activa, y la tasa pasiva.

La tasa activa es la que las entidades financieras cobran a los clientes por los préstamos de dinero. Constituye la "ganancia” o el lucro de la entidad- también llamada spread bancarioporque representa el precio que los bancos ponen a su dinero. Es el precio que el banco establece como contraprestación por haberse privado del uso de su capital, en favor de un cliente.

La tasa pasiva, por el contrario, es aquella que paga el intermediario financiero a los particulares que colocan en ella su dinero. Es decir, es el precio que el banco pone al dinero de sus depositantes. Es lo que la entidad está dispuesta a pagar a los particulares, por la privación del uso del dinero que éstos han puesto a disposición de ella durante cierto lapso -v.g., en un plazo fijo-.

\footnotetext{
10 Al respecto, resulta ilustrativo el voto en disidencia del Dr. Hitters en la causa 119.176, "Cabrera" del 15/6/2016, en donde cita doctrina en ambos sentidos. También es interesante su postura, que concluye que será el juzgador de origen quien deberá seleccionar en cada asunto, la tasa aplicable para la determinación del interés judicial moratorio, siempre dentro de las alternativas plurales que permite la actual doctrina legal en la materia (tasa pasiva). Claro que -en nuestra opinión, y con el respeto que nos inspira la autorizada opinión del cortesanoello otorga una libertad a los jueces de grado, para la que no siempre podemos tener por garantizada una aptitud razonable; además de generar (más) desigualdades entre justiciables.
} 
Por supuesto que existirá una diferencia entre ambas, en virtud de la cual la entidad generará su lucro, poniendo a "trabajar" el dinero en operaciones financieras.

A su vez, dentro de los dos grandes ámbitos de tasa pasiva y activa, existen subgrupos, definidos por diversas operaciones financieras. Dentro de las tasas activas que podemos encontrar, se encuentran la tasa activa por descubierto en cuentas corrientes, por financiación de saldos en tarjetas, etcétera, siendo la más común la "Tasa activa por operaciones de descuento a 30 días". Dentro de la denominada tasa pasiva, tenemos las de plazos fijos a 30 o 180 días, la que se paga en cuentas de ahorro en pesos, y la famosa tasa pasiva "digital", que es la que se paga por plazos fijos digitales a 30 días. Esta última suele ser la más alta en nuestros días, en la Provincia de Buenos Aires.

Respecto de la elección de la tasa, de existir varias posibles -como hoy sucede-, la misma será realizada por el juez. Esta libertad, en nuestra ley actual, se limita a aquellas tasas que se fijen en las reglamentaciones del Banco Central (art. 768 inc. c).

No debemos olvidar al respecto, que la determinación de la tasa aplicable es una cuestión propia de los jueces de grado. Así lo ha entendido la CSJN en varias oportunidades ${ }^{11}$ : "La determinación de la tasa de interés a aplicar como consecuencia del régimen de la ley de convertibilidad 23.928, no constituye cuestión federal susceptible de habilitar la instancia extraordinaria, sino que queda ubicada en el espacio de la razonable discreción de los jueces de la causa que interpretan dicho ordenamiento, sin lesionar garantías constitucionales, en tanto sus normas no imponen una versión reglamentaria única del ámbito en cuestión." (CSJN, fallos 323:2122, donde se cita el precedente Banco Sudameris de Fallos: 317:507 que a su vez remite a los votos en disidencia de la causa L.44.XXIV. "López,

\footnotetext{
11 Se destaca que estos fallos fueron dictados en vigencia del Código Civil según ley 340. En nuestra ley actual, la posibilidad de elección del juez se limita, como aclaramos al campo de las que establezcan las reglamentaciones del Banco Central (art. 768 inciso c).
} 
Antonio Manuel c/ Explotación Pesquera de la Patagonia S.A. s/ accidente - acción civil" del 10 de junio de 1992).

Y entonces, ¿qué tasas entran en juego en las indemnizaciones por daños y perjuicios?

Más allá de sus implicancias financieras, a los operadores del derecho nos ha ocupado por largo tiempo la discusión acerca de cuál es la tasa que debe pagar un deudor perdidoso en juicio, a su acreedor. Recordemos que la función de los intereses, parece ser la de aportar un equilibrio, manteniendo el valor del que se ha visto privado el acreedor y también compensándolo por todo el tiempo en que no tuvo ese bien disponible. Y aquí es donde deben conjugarse otros valores deseables, como la estabilidad económica, buscada por medio de las políticas de estado. La cuestión es analizada de manera detallada por nuestra CSJN en el fallo López, Antonio Manuel c/ Explotación Pesquera de la Patagonia S.A antes citado.

En este sentido, son loables las políticas que tienden a evitar la inflación monetaria -v.g., la ley 23.928 en tanto prohíbe la indexación de deudas-, pero su aplicación debe conjugarse con la realidad económica. Así, es y ha sido tarea de nuestros tribunales la de analizar cuál de las tasas de interés establecidas por los bancos oficiales puede sopesar mejor estos dos fines: no perjudicar al acreedor pero tampoco perjudicar las políticas monetarias que tienden a evitar la inflación de la moneda.

Ante la ausencia de una normativa reglamentaria específica sobre alícuotas en concreto, se han expedido los tribunales superiores, sentando una doctrina que en general ha sido acatada por los jueces inferiores.

En nuestro ámbito local, la SCBA consideró que es aplicable - a partir de la entrada en vigencia del CCCA- la Tasa Pasiva más alta -refiriéndose a la digital o BIP- en la causa 119.176, "Cabrera, Pablo David contra Ferrari, Adrián Rubén s/ Daños y perjuicios", sentencia del 15 de Junio de 2016. Sin perjuicio de resultar un fallo trascendente, en el mismo se incurre en la 
imprecisión de establecer que se deben estos intereses desde la fecha del hecho dañoso.

La cuestión queda luego corregida en "Nidera S.A. contra Provincia de Buenos Aires. Daños y perjuicios" (causa 121.134, del 03/05/18). Allí la Corte Provincial, sentó que para el cálculo de los intereses deberá aplicarse la alícuota del $6 \%$ anual, la que corresponderá ser impuesta al crédito indemnizatorio establecido en la sentencia, y hasta el momento tenido en cuenta para la evaluación de la deuda (arts. 772 y 1.748, Cód. Civ. y Com.). Esta determinación, sostiene el cimero tribunal, encuadra en una modalidad "no indexatoria", teniendo en cuenta que en la sentencia, las sumas han sido fijadas conforme "valores actuales", justamente por tratarse de una deuda de valor.

El criterio parece adecuado, y es concordante con las conclusiones de las XXVI Jornadas de Derecho Civil de 2017, en donde se concluyó que mientras la obligación sea de valor y no haya sido cristalizada en una deuda dineraria, debe aplicarse una tasa de interés puro. Esto es, para el plazo que va desde el momento del hecho y la sentencia que fija en dinero la indemnización a valores actuales.

De allí en más, resultará aplicable la tasa de interés establecida en las causas C. 101.774, "Ponce"; L. 94.446, "Ginossi" (sents. de 21-X-2009) y C. 119.176, "Cabrera" (sent. de 15-VI2016), esto es, la tasa pasiva más alta fijada por el Banco de la Provincia de Buenos Aires en sus depósitos a treinta días, vigente al inicio de cada uno de los períodos comprendidos.

La Corte nacional, por su parte, tiene sentado que los intereses moratorios "constituyen la consecuencia inmediata $y$ necesaria del incumplimiento de la obligación, pues tienen por objeto resarcir el lucro perdido por el acreedor al no poder aplicar el capital adeudado a una inversión que genere la renta pertinente, vale decir los intereses que aquél ha dejado de percibir. Desde esta perspectiva, el daño debe liquidarse mediante la aplicación de la tasa bancaria pasiva, pues esta es la que hubiera obtenido el accipiens de haberle sido restituido el 
capital en tiempo oportuno (Fallos: 315:158, considerando 36)" (CSJN C.412.L. del 11/7/2019 entre otros) ${ }^{12}$.

\section{La prohibición de indexación y/o actualización monetaria y la cuantificación de un valor}

Muchas veces se ha suscitado una confusión entre las operaciones de indexación -recordamos, prohibidas en nuestro sistema- y las de determinar el monto en dinero, de una deuda de valor.

La jurisprudencia se ha encargado de dividir las aguas, estableciendo que no se debe identificar la estimación de los rubros indemnizatorios a fin de reflejar los valores actuales de los bienes a los que refieren, con la utilización de mecanismos indexatorios, de ajuste o reajuste según índices o de coeficientes de actualización de montos históricos.

El matiz diferencial entre ambas modalidades se basa en que en la indexación, nos encontramos ante una operación matemática, mientras que la determinación de una deuda de valor, en principio no consiste estrictamente en eso, sino en el justiprecio de un valor según la realidad económica existente al momento en que se pronuncia el fallo (conf. doctr. causas Ac. 58.663, "Díaz", sent. de 13-II-1996, Ac. 60.168, "Venialga", sent. de 28-X-1997 y C. 59.337, "Quiroga", sent. de 17-II-1998, e.o.).

Creemos que hay aquí una cuestión esencial: la prohibición de indexación toma vigencia sólo ante la existencia de una deuda de dinero. Es por eso que no puede hablarse de indexación o actualización en deudas de valor.

La diferencia puede ser sutil, pero lo cierto es que, como dijimos, las deudas de dinero no deben ser indexadas -so pretexto de querer resguardar su valor-, por expresa prohibición

\footnotetext{
12 Sin perjuicio de ello, existen plenarios como el conocido "Samudio" del año 2009 en que las Cámaras Nacionales en lo Civil han avalado la aplicación de la tasa activa para el interés moratorio.
} 
legal. Mientras que en las deudas de valor la indexación no tiene ni puede tener lugar, porque las deudas de valor simplemente se traducen a dinero, se cuantifican. Esa cuantificación lo será en la cantidad de dinero que, al momento de realizarla, represente el "valor debido". Su propio concepto puede implicar que, justamente por deberse un valor, se mantengan en cierto modo "actualizadas" -sólo hasta el momento en que se conviertan en dinerarias-. Pero eso no responde a una operación indexatoria, sino a una mutación de su objeto que resulta necesaria y en general, tendiente a su cancelación.

\section{Los dilemas actuales}

En muchos casos se ha entendido que los diversos tipos de intereses deben sopesar, a más de la privación del uso del capital, la pérdida de su valor adquisitivo. Lo cierto es que esto, en el ámbito de las obligaciones dinerarias constituye, al menos esencialmente, en una operación de actualización que en nuestra ley actual está expresamente prohibida, y que no podría el juez dejar de lado sin tildarla de inconstitucional.

Sin perjuicio de ello, en nuestros tiempos, cualquier abogado que ejerce la profesión puede ver cómo, ante la duración excesiva de los procesos y la constante depreciación de la moneda de curso legal, las indemnizaciones en muchos casos llegan al momento de su cobro perjudicadas por una notable pérdida de su valor. Esto no puede sino percibirse como un menoscabo para el acreedor, el justiciable. Esta desvalorización no siempre logra ser neutralizada mediante la aplicación de los intereses que corresponden según la doctrina vigente.

En este sentido, se expidió la doctrina en las XXVI Jornadas de Derecho Civil, en donde se expuso el dilema de los intereses y la depreciación monetaria, y en sus conclusiones se lee: " $E l$ correcto funcionamiento del principio nominalista supone la estabilidad monetaria. Las situaciones inflacionarias conducen a una alteración de las funciones de los intereses que no se compadece con su noción tradicional". 
La pregunta que cabe hacerse como presupuesto es, ¿es función de los intereses la de mantener el valor del dinero? Si la respuesta es afirmativa, resulta evidente que los establecidos por la doctrina jurisprudencial actual, resultan insuficientes. Creemos, como bien lo ha advertido la doctrina, que es el principio nominalista rígido el elemento que ha contribuido a desfasar el sistema. Todo el régimen de las obligaciones dinerarias se basa, entendemos, en una premisa meramente dogmática, que no encuentra sustento en la realidad monetaria argentina. Prueba de ello es que, mediante algunos mecanismos -como el de recurrir a tasas de interés activas o métodos indirectos de actualización -, se ha pretendido paliar su rigidez. Pero claro, ello queda al arbitrio del judicante en cada caso, circunstancia que no ofrece garantía alguna, menos aun teniendo en vista las doctrinas actuales de los tribunales superiores.

En el análisis de la cuestión no debe perderse de vista que resulta loable el fin que se persigue con el régimen nominalista, cual es evitar la producción o agravación de procesos inflacionarios o de desvalorización de la moneda, mediante la aplicación libre de mecanismos de indexación, cualesquiera sean. Sin embargo, creemos que la rigidez con que se ha aplicado el nominalismo -el que hoy nos rige ha sido establecido en circunstancias económicas particulares como la vigencia de la convertibilidad-, no siempre ha conducido a soluciones equilibradas. Nuestro actual sistema -legal y jurisprudencialcontinúa, al día de hoy, cargando con la deuda de adecuarse a la realidad. 